\section{Edycaçäa

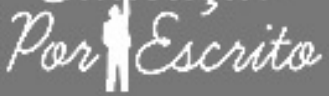

ARTIGO

\section{Editor}

Alexandre Anselmo Guilherme PUCRS, RS, Brasil

\section{Editor Assistente}

Cibele Cheron

PUCRS, RS, Brasil

\section{Editores Associados}

Bruno Antonio Picoli

Universidade Federal da Fronteira Sul, Chapecó, SC, Brasil

Pricila Kohls dos Santos

Universidade Católica de Brasília,

Brasília, DF, Brasil

Renato de Oliveira Brito

Universidade Católica de Brasilia,

Brasilia, DF, Brasil

Elisa Ustarroz

PUCRS, Porto Alegre, RS, Brasil

\section{ISSN 2179-8435}

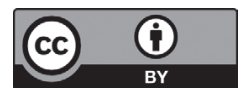

Este artigo está licenciado sob forma de uma licença Creative Commons Atribuição 4.0 Internacional, que permite uso irrestrito, distribuiçăo e reproduçāo em qualquer meio, desce corretamente citada

\title{
Múltiplos olhares de estudantes de um curso de licenciatura sobre a docência orientada: reflexões necessárias
}

Multiple views of students from a degree course about oriented teaching: necessary reflections

\author{
Mariane Carloto da Silva $\oplus^{1}$ \\ Sandra Regina Costa Pereira ${ }^{1}{ }^{1}$ \\ Silvia Maria de Oliveira Pavão 1 \\ ${ }^{1}$ Universidade Federal de Santa Maria (UFSM), Santa Maria, RS, Brasil.
}

\section{RESUMO}

O artigo apresenta os resultados de uma pesquisa sobre Docência Orientada desenvolvida em uma Universidade Federal de ensino localizada no Estado do Rio Grande do Sul. O objetivo geral proposto foi investigar as percepções dos estudantes de um curso de licenciatura em relação à Docência Orientada. Optou-se por um enfoque qualitativo de caráter exploratório-descritivo. A análise dos dados se deu por meio da técnica de Análise de Conteúdo (BARDIN, 2011), sendo apresentados em duas categorias: 1) Docência Orientada e as estratégias de ensino e 2) Dimensões da Docência sob a perspectiva dos estudantes. Concluiu-se que a Docência Orientada contribuiu para a apropriação dos conhecimentos ensinados durante a disciplina, principalmente pela presença de três docentes na sala, e que ainda é necessário fazer ajustes em relação à forma de apresentação da Docência Orientada proposta aos estudantes da Graduação, sendo importante a ampliação do exercício dessa diante do potencial formativo para todos os envolvidos.

Palavras-chave: Educação Superior. Docência Orientada. Formação docente.

\section{ABSTRACT}

This paper presents the results of a research about Oriented Teaching developed in an University federal education located in Rio Grande do Sul state. The main goal proposed was to investigate the perceptions of the students from a degree course regarding the oriented teaching. It was opted for a qualitative exploratory descriptive approach. The analysis of the data was made by the Content Analysis technique (BARDIN, 2011), being presented in two categories: 1) Oriented Teaching and teaching strategies and 2) Dimensions of Teaching 
from the perspective of students. The conclusion is that the Guided Teaching contributed to the appropriation of the knowledge taught during the course, mainly by the presence of three teachers in the room, is that it is still necessary to make adjustments regarding the way Oriented Teaching is proposed for undergraduate students, it is important the enlargement of Oriented Teaching practice because of its potential in the formation of all people involved.

Keywords: Higher education. Oriented teaching. Teaching formation.

\section{Introdução}

s exigências atuais no campo da Educação têm demonstrado a necessidade de buscar melhor qualificação profissional, uma formação de professores reflexivos que se disponha a rever suas práticas pedagógicas e seu aprimoramento, oferecendo melhores resultados no campo educacional. Não resta dúvida de que os cursos de formação continuada Strictu Sensu, Mestrados e Doutorados, têm revisado a prática de capacitação de seus estudantes buscando ampliar seu espaço de atuação, muitas vezes limitado apenas para a pesquisa. Há um movimento e uma preocupação crescente com o comprometimento concomitante com o ensino, a pesquisa e a extensão, oportunizando aos pós-graduandos a aquisição de conhecimentos e habilidades para o exercício docente e a sua importante função social.

Nesse caso, incluir a Docência Orientada como disciplina aos estudantes dos cursos de Mestrado e Doutorado é uma forma de ofertar um espaço de ação onde possa se constituir um educador que alie o conhecimentos da sua realidade social, da sua formação inicial e do seu conhecimento em pesquisa e investigação. Então, a Docência Orientada é para o pós-graduando o "momento em que ele realiza sua formação inicial, ingressa na carreira docente, necessita de apoio e pessoas mais experientes que, de certa forma, o 'conduzam' em seus primeiros contatos com a sala de aula" (NEUENFELDT, 2008, p. 56).

Essa organização de saberes adquiridos ao longo de sua formação pessoal, acadêmica e profissional possibilita trocas importantes no processo de interação entre docente orientador e futuros docentes. Nesse caso se enquadram os estudantes de pós-graduação como docentes orientados, e enfrentam, em última análise, o desafio de "aprender a aprender”, sempre tão atual, permanente e necessário à toda profissão e condição humana.

Todavia, sabe-se que a aprendizagem foi mediada por muito tempo por uma atuação docente reduzida a mera transmissão de conteúdos, na qual o professor mantinha a detenção do saber, e os estudantes eram meros sujeitos 
passivos, em ambientes onde a motivação não era favorável à autoconstrução humana de nenhum dos envolvidos nesse processo.

Assim, a prática reflexiva sobre o processo de ensino-aprendizagem leva à certeza de que serão corriqueiras e constantes as mudanças, pois "onde há vida, há inacabamento [...]" (FREIRE, 1996, p. 50), portanto, o docente precisa perceber sua formação e sua prática como inacabada de experiências, de saberes, de aprendizagens, de envolvimentos, sendo necessárias construções permanentes.

Cabe destacar que a Docência Orientada se configura como importante na preparação e concretização do ser professor na Educação Superior, especialmente, por acreditar-se que “[...] não basta que o professor tenha um conhecimento aprofundado de uma área específica do conhecimento, ele precisa ter uma formação que contemple diversos aspectos, inclusive os pedagógicos" (NEUENFELDT, 2008, p. 74). Dessa forma, levantamos as seguintes questões: como os estudantes da graduação avaliam a proposta de inserção de docentes orientadas e suas práticas no contexto de sala de aula na condição de professoras da disciplina? Quais as contribuições da Docência Orientada para os estudantes de graduação que estão em processo de formação docente e que tiveram a atuação das mestrandas?

Nesse sentido, este estudo tem por objetivo geral investigar as percepções dos estudantes de licenciatura em Educação Especial em relação à Docência Orientada. Estabeleceram-se como objetivos específicos: analisar os documentos que orientam a prática da Docência Orientada na Instituição; refletir sobre as concepções da Docência Orientada no processo formativo dos estudantes do curso de licenciatura; discutir sobre aspectos positivos e negativos da Docência Orientada elencados pelos estudantes do curso de Licenciatura; incentivar o pensamento crítico-reflexivo dos estudantes da graduação sobre a prática da Docência Orientada encorajando a verbalização de suas concepções sobre tal experiência.

A partir das possíveis reflexões advindas das perspectivas dos estudantes da graduação sobre a Docência Orientada, fortalece-se a importância da escuta do outro no lugar que ele ocupa, buscando aceitar seu pensamento e refletir de que forma a ação docente está contribuindo no processo formativo dos futuros educadores, "testemunhar a abertura aos outros, a disponibilidade curiosa à vida, a seus desafios, são saberes necessários à prática" (FREIRE, 1996, p. 135-136). A partir de uma perspectiva de relação dialética, na qual quem ensina aprende e simultaneamente quem aprende também ensina, possibilita por fim, uma autorreflexão crítica sobre os resultados.

\section{Contextualizações iniciais}

Atualmente há o reconhecimento de que o contexto acadêmico é mutante e que a prática docente se depara com diversas realidades, isto requer concordar com a premissa de que as situações concretas não são controladas. 
Portanto, interrupções, percalços podem surgir ao longo de uma aula, e nesse momento, o planejado pode requerer adaptações rápidas.

Enfrentar tais situações com o apoio do orientador docente significa criar em conjunto competências e orientações que poderiam ser construídas sem os princípios didáticos e pedagógicos necessários, desprovidos do necessário diálogo e olhar crítico, nesse sentido, é defendida aqui a ideia de que os sujeitos se constroem melhor quando repensam suas práticas de forma participativa e em constante diálogo com seus pares.

Foi a partir dessa perspectiva que este trabalho foi construído, com discussões entre duas mestrandas, aqui também denominadas de docentes orientadas, e uma orientadora, professora de carreira do Magistério Superior responsável pela supervisão da atuação das mestrandas ao longo da disciplina denominada Docência Orientada. A disciplina está vinculada ao Programa de Pós-Graduação em Educação, no nível Mestrado de uma Universidade Federal do estado do Rio Grande do Sul. A Docência Orientada é praticada nos cursos de Graduação, na própria universidade, sendo necessário que a professora orientadora seja também a professora responsável pela disciplina ofertada aos alunos da Graduação.

A Docência Orientada encontra-se instituída no Regimento Interno de Pós-Graduação Stricto Sensu e Lato Sensu da instituição que estabelece aos alunos de cursos de Mestrado e Doutorado a possibilidade exercer a docência no Ensino Superior, totalizando até dois créditos aos alunos de cursos de Mestrado e quatro créditos aos alunos de cursos de Doutorado. O exercício da Docência Orientada será realizado com acompanhamento constante do professor orientador.

Algumas novidades enriqueceram a prática: a quantidade de docentes orientadas na realização da disciplina e a parceria firmada entre ambas. Em relação à quantidade de docentes orientadas, duas mestrandas se dividiram para o desenvolvimento das atividades de docência; quanto à parceria firmada, acordou-se que, embora a carga-horária da Docência Orientada fosse de 15 (quinze) horas, as observações, trocas e o aprendizado seriam mais consistentes se participassem ao longo de toda a disciplina ofertada à Graduação que compreendia uma carga-horária de 60 (sessenta) horas.

A dinâmica de presença das três docentes ao longo de todos os encontros foi decidida entre as próprias docentes, momento em que a professora orientadora destacou a necessidade de cumprimento do regimento.

A disciplina possuiu o objetivo de colaborar para a complementação da formação pedagógica das pós-graduandas em atividades de ensino na Educação Superior, por isso, as atividades de ensino e a avaliação das práticas docentes foram desenvolvidas de forma individualizada, seguindo uma divisão prévia dos conteúdos a serem ministrados.

Por meio das experiências vividas em uma sala de aula na Educação Superior reconhece-se a importância da prática reflexiva da atuação docente, possibilitando a melhoria de estratégias de ensino, empatia, sentimentos 
frente aos estudantes, sem esquecer-se de ouvir aqueles que estão percebendo as contribuições da atuação, no caso, os estudantes. É nesse sentido que as relações e ideias em um grupo podem se concretizar, oportunizando o desenvolvimento da mudança, superação da insegurança, incerteza e imprecisão (SCHÖN, 2000).

Esse espírito de mediar situações de aprendizagem, de observar, refletir, planejar situações que progridam o conhecimento são competências profissionais que precisam emergir nas práticas dos professores, competências estas que variam e privilegiam as necessidades da atualidade, a partir dos estudantes, dos erros, dos entraves para o sucesso e conclusão do curso escolhido (PERRENOUD, 2000).

Estas posturas estão inerentes à profissão de professor, apreendido desde a formação inicial estendendo-se em toda trajetória profissional. É importante acrescentar que a prática se torna formativa quando há disposição e interesse por parte docente em refletir na e sobre a prática que desenvolve.

\section{Docência orientada: aproximações com o campo}

A Educação Superior tem buscado além desses aspectos um crescente comprometimento científico de suas atividades, sempre testando, pesquisando e analisando as suas práticas e os resultados alcançados por meio delas. Destacamos a primeira finalidade da Educação Superior elencada na Lei de Diretrizes e Bases da Educação (LDBEN) que é a estimulação da criação cultural e do desenvolvimento do espírito científico, sem esquecer-se do pensamento reflexivo (BRASIL, 1996). Parece-nos evidente que o caminho para atender a essa proposta é não dissociar os subsídios teóricos dos práticos, para que a formação profissional daqueles que estão nas universidades na condição de acadêmicos da Graduação, do Mestrado ou Doutorado possam, de fato, ultrapassar a mera reprodução de pensamentos organizados esquematicamente e alcançar maior solidez em suas formações e, por conseguinte, em suas práticas.

O que se busca é a construção de um professor reflexivo sobre sua própria prática, não um ser pronto, apto para fornecer todas as respostas às situações que sequer experimentou. Para isso defende-se a importância do feedback do trabalho realizado, o retorno avaliativo constante para os estudantes que desenvolvem a disciplina de Docência Orientada e, por isso, estão intimamente envolvidos no processo de ensino-aprendizagem de múltiplos sujeitos.

Não obstante as finalidades concernentes à Educação Superior, a Universidade precisa oportunizar a formação profissional para inserção no mercado de trabalho e, para isso, precisa desenvolver ainda o espírito de colaboração e trabalho em equipe (BRASIL, 1996).

Uma inquietação das autoras é de que os programas precisam preparar os alunos dos cursos Strictu Sensu também para a docência, evitando que mestrandos e doutorandos alimentem a falsa compreensão de que ao longo 
de vinte e quatro ou quarenta e oito meses respectivamente a sua preocupação deva se restringir apenas à pesquisa, ou que seja suficiente prática, meramente conteudistas e imutáveis. Nesse sentido, Neuenfeldt (2008, p. 121) ressalta que "a Docência Orientada pode ser um espaço de vivenciar a docência antes de assumir a regência como professor, possibilitando compreender melhor de que lugar se está falando e conseguir aliar a teoria e a prática [...]".

Diante disso, pode-se afirmar que o contexto universitário é pluridisciplinar, pois busca o domínio e cultivo do saber humano em sua forma mais ampla, por isso a proposta de que um terço do corpo docente tenha pelo menos a titulação acadêmica de Mestrado ou Doutorado deve ser visto como a busca por uma melhor qualificação e capacidade teórico-prática desses sujeitos (BRASIL, 1996).

Parece prudente extrair o artigo 52 da Lei de Diretrizes e Bases da Educação (LDBEN) (BRASIL, 1996), que prevê uma exigência mínima de mestres e doutores na Educação Superior, acredita-se que tal regulação se deu com o intuito de ofertar melhor qualidade ao corpo docente universitário, torna-se impensável por essa lógica conceber que os programas não exijam que seu alunado se submeta a experiência da Docência Orientada.

A ótica é que este momento é singular, pois muitos que ainda não puderam vivenciar o papel de professor universitário por fatores diversos, que perpassam desde o receio de cometer erros, a não identificação com a docência ou por considerar algo trabalhoso e complexo, vão poder perceber por meio da prática o contexto de trocas e experiências significativas de aprendizagens e fértil campo de pesquisa.

Ao se pensar nos processos de formação docente, vários lugares possibilitam a construção do ser professor, e seguindo nessa perspectiva, vincula-se às discussões ao campo da Educação Superior, especialmente na disciplina de Docência Orientada, por acreditar que sejam fundamentais para o desenvolvimento de saberes os momentos de práticas reflexivas, o compartilhamento de experiências, a escuta dos estudantes sobre a prática que vem sendo desenvolvida e possibilidade de aquisição do conhecimento.

Considera-se que a disciplina Docência Orientada tem grande relevância no processo formativo docente e na reflexão sobre a prática, além de exercitar a escuta dos estudantes, identificando o que eles pensam, como avaliam o trabalho desenvolvido, quais as contribuições para o processo de ensino-aprendizagem. Se não houver a valorização do outro (estudantes) não há possibilidades de (re) construções da atuação docente.

Aponta-se o que diz Freire (1996, p. 33), ao afirmar que não há prática educativa sem pensar os seres humanos que estão envolvidos e por isso que "[...] transformar a experiência educativa em puro treinamento técnico é amesquinhar o que há de fundamentalmente humano no exercício educativo: o seu caráter formador".

Frente a isso, defendem-se ações reflexivas no exercício da docência, principalmente nas atividades de Docência Orientada, por ser dada total responsabilidade formativa durante seu exercício, pois em sala de aula equiparam-se às mesmas responsabilidades às dos professores orientadores. 
As considerações propostas surgem a partir de experiências vivenciadas e de delineamentos metodológicos colocados em prática, o que oportunizou estabelecer concepções durante o exercício e continuar com o sentimento de inacabamento que instiga a buscar o melhoramento e progresso na atuação. Com isso, reitera-se que ser professor prevê a constituição de práticas reflexivas.

\section{Docência Orientada como espaço de reflexão docente}

Tem-se consolidado que não há uma formação docente estanque e finalizada, mas sim, composta ao longo de todo o percurso educativo que envolve estudos, perspectivas, ideias de formação permeadas pela vivência prática, por momentos de reflexão. Ao longo da trajetória profissional o professor ressignifica suas práticas com aquilo que é vivido, com a realidade presente no dia-a-dia da profissão.

De acordo com Isaia; Cunha (2006, p.375), a Docência Orientada é uma "experiência compartilhada do(a) professor(a) que está se qualificando no curso de Pós-Graduação em Educação com um professor orientador, responsável pela disciplina no espaço da docência no Ensino Superior.

Nesse sentido destaca-se que a docência na Educação Superior se faz coletivamente, e que implica em trocas de experiências, de diálogos e de discussões teóricas e práticas, já que se atua com pessoas com uma bagagem social e cultural, todos são aprendentes e ensinantes nesses espaços. Não é possível ser professor se não houver abertura para a mudança e escuta. Freire (1996, p.97) acrescenta que "precisamos aprender a compreender a significação de um silêncio, ou de um sorriso ou de uma retirada da sala [...]", isto que faz a prática reflexiva docente, voltar-se aos estudantes envolvidos no processo de ensinar e aprender, interpretar suas empatias, seus comportamentos.

Assim, pode-se afirmar que a prática e a reflexão andam juntas e que a abertura de espaços para expressões dos estudantes favorece a qualidade de ensino, aperfeiçoamento, e consequentemente uma melhor formação acadêmica.

Para tal intento utiliza-se os dizeres de Schön (2000, p. 32) quando enfatiza que "[...] estamos aptos a executar sequências fáceis de atividade, reconhecimento, decisão e ajuste sem ter, como se diz, que pensar a respeito". O pensar a respeito envolve a reflexão da ação, isso porque nem sempre a prática nos revela os conhecimentos e aprendizagens, mas sim, o ato de refletir antes, durante e depois da ação.

Diante disso, os estudantes não devem ser apenas telespectadores da nossa prática, ao contrário, são protagonistas, que apenas com um olhar conseguem atribuir significados, sentimentos de valor (como positivo ou negativo) sobre os aspectos didático-pedagógicos. Tornando o olhar para a Docência Orientada esta coloca-nos na posição de aprendentes, na construção de um profissional que atenda a demanda da Educação Superior. Compartilha-se com as 
proposições de Freire (1996, p. 38), quando afirma que “[...] é pensando criticamente a prática de hoje ou de ontem que se pode melhorar a próxima prática" (FREIRE, 1996, p. 38).

O exercício da Docência Orientada envolve técnicas, perspectivas diferenciadas destinadas à formação humana, abertura ao pensamento crítico, supera-se o foco técnico do ensino, pois para o desenvolvimento das atividades e realização das avaliações precisa-se da participação e do comprometimento além do relacionamento com o outro (neste caso o professor orientador e os estudantes da graduação). Estes aspectos são fundamentais para o exercício de qualquer docência.

Os saberes da formação profissional transmitidos aos professores durante o processo de formação inicial e/ ou continuada precisam estar conectados aos saberes disciplinares que são aqueles reconhecidos e identificados como pertencentes aos diferentes campos do conhecimento. Estes, por sua vez, não podem se desvencilhar dos saberes curriculares - apresentados sob a forma de objetivos, conteúdos e métodos facilmente identificados nos programas de disciplina, e sob nossa ótica, todos eles direcionam e colaboram para o alcance dos saberes experienciais - que resultam do próprio exercício da atividade profissional dos professores (TARDIF, 2002).

Os saberes experienciais têm sido suplantados pela preocupação conteudista e tecnicista que as formações acabaram tomando no Brasil, esses saberes só são possíveis de adquirir por meio de vivências no espaço acadêmico onde exista a possibilidade de relações entre professores e seus pares além de professores e estudantes.

A partir disso constata-se que um estudo mais detalhado sobre Docência Orientada se faz necessário, para isso lança-se a proposta de adotar uma metodologia específica que será detalhada a seguir.

\section{Metodologia}

Toda pesquisa perpassa pelo panorama da apropriação teórica e não se desvencilha do comprometimento com a ética, a construção de conhecimentos e com o outro, constituindo-se assim em uma tarefa árdua e complexa que precisa repercutir na construção de conhecimentos significativos para toda a sociedade, do contrário torna-se desnecessária.

Diante disso, destaca-se que este trabalho é alicerçado no enfoque qualitativo, por considerar que tal abordagem de investigação proporciona profundidade aos dados, além de riqueza interpretativa, contextualização do ambiente, e ainda apreensão de detalhes e experiências únicas contidas no contexto educacional, servindo assim para investigar as percepções dos participantes da pesquisa (SAMPIERI; COLLADO; LUCIO, 2013).

Quanto aos objetivos do estudo concorda-se com Prodanov e Freitas (2013) que consideram a aproximação das pesquisas descritivas e exploratórias no sentido de propiciarem uma nova visão do problema, portanto, 
o estudo exploratório atende ao interesse da pesquisa que busca novas perspectivas e ampliação dos estudos já existentes sobre Docência Orientada e se preocupa com a atuação prática, enquanto o estudo descritivo oferta a descrição das características dos participantes a partir de suas falas e o estabelecimento de relações entre variáveis.

Neste trabalho foram envolvidos os seguintes procedimentos técnicos para levantamento de dados: busca por material bibliográfico, projeto pedagógico e regimento interno do curso de Mestrado da instituição e um questionário aplicado ao término da disciplina.

A busca bibliográfica acerca da temática deste estudo foi uma das etapas que auxiliou na organização e disposição de todo o referencial teórico apresentado. O acesso ao projeto pedagógico e regimento interno do curso de Mestrado no qual as docentes estão vinculadas se deu por meio do site da universidade.

Os participantes responderam a um questionário com quinze questões e totalizaram 24 (vinte e quatro) estudantes de um curso de licenciatura de uma universidade pública do estado do Rio Grande do Sul que tiveram a Docência Orientada. Na apresentação dos resultados, tiveram seus nomes mantidos em sigilo, sendo identificados apenas com uma letra maiúscula seguida de um número, utilizando-se a seguinte apresentação: A1, A2, A3 e assim sucessivamente até $\mathrm{A} 24$, último participante.

Na sequência, mostra-se a análise dos dados obtidos com o questionário, realizada por meio da técnica de Análise de Conteúdo, procedendo inicialmente a sua categorização que é essencialmente a classificação de elementos constitutivos de um conjunto por diferenciação, e depois por reagrupamento que tem em seu critério de categorização o aspecto semântico, sintático, léxico e expressivo (BARDIN, 2011).

\section{Resultados e discussões}

Apresentam-se duas categorias de análise nas quais problematizam aspectos considerados essenciais ao campo em discussão, as categorias são as seguintes: 1) Docência Orientada e as estratégias de ensino e 2) Dimensões da Docência sob a perspectiva dos estudantes.

\section{Docência orientada e as estratégias de ensino}

Nesta categoria pretendeu-se realizar uma reflexão sobre a prática desenvolvida na disciplina de Docência Orientada sob as concepções dos estudantes em relação à importância da Docência Orientada em seu processo formativo, dando ênfase a alguns aspectos como a presença de três professoras, sendo uma professora/orientadora e duas mestrandas/docentes orientadas, durante todo o semestre letivo, a metodologia utilizada, organização do programa 
da disciplina, o espaço para participação dos estudantes ao longo das aulas e ainda a avaliação do desempenho das mestrandas em relação à explanação dos conteúdos.

A certeza de que a prática docente é necessária na formação do professor, mesmo que este se lance apenas à pesquisa no futuro, já foi abordada anteriormente, portanto, há de se fazer a aproximação entre a teoria e o espaço de atuação e para isso são indispensáveis a união de várias competências ou saberes docentes no contexto dessa prática. Mediadas pelo sentimento investigativo e reflexivo de toda a atuação e atividades executadas, acredita-se que a partir das respostas dos estudantes é possível enxergar o trabalho do professor.

Embora autores como Perrenoud (2002), Tardif (2002), Franco (2008a; 2008b), Oliveira e Vasconcelos (2011) sustentem que a formação de professores deve servir ao propósito de dar condições de lançar mão de aportes teóricos e metodológicos para viabilizar a instrumentalização das ações docentes de forma reflexiva, tradicionalmente a sociedade e as formações têm priorizado e valorizado o acúmulo de conhecimentos teóricos colocando-os até mesmo acima da prática.

Franco (2008b) considera que o percurso formativo do professor precisa desprender-se da prática tecnicista historicamente utilizada, onde os bons professores eram aqueles que conseguiam normatizar e prescrever suas práticas, sem necessidade de criação e reflexão sendo apenas executores de um planejamento, técnicos de sala de aula. Completa afirmando que a metodologia formativo-emancipatória requer a presença concomitante de várias competências que envolvem processos criativos e intuitivos que se organizam durante a ação docente e decorre de respostas aos conflitos, acrescenta-se a isso a preparação para atender as dúvidas e demandas vindas dos estudantes.

A compreensão de que a Docência Orientada é voltada para a aprendizagem apenas dos estudantes da Graduação que estão em formação inicial também pode descaracterizar a finalidade de troca de experiências e práticas, pois mesmo quando não há a participação direta e ativa ao longo de toda a disciplina, as docentes orientandas exercitam sua formação continuada por meio da observação da prática.

Sendo assim, defende-se a escuta dos estudantes em relação ao ensino ministrado por duas docentes orientadas com a presença da professora orientadora, por acreditar que "[...] a docência é prática permanente na relação professor-aluno-conhecimento, em que ensinar, aprender, pesquisar e avaliar são dimensões da didática para o trabalho do professor crítico, compromissado, ético, dialeticamente constituído" (VEIGA, 2012, p. 8). Nesse intento, em toda prática desenvolvida é imperativo que realmente ocorra uma preocupação com as percepções dos estudantes para aprimoramento profissional.

A8 e A13 explicitam suas percepções críticas com relação à presença de três docentes: "talvez nem sempre as três presentes, ou para aproveitar a presença de todas, seria melhor ouvir a opinião de cada uma" (informação 
verbal) $^{1}$, e "não precisaria de três professores em sala de aula. Duas seriam suficientes" (informação verbal)2. Esses dizeres retratam um desconhecimento com relação à dinâmica de desenvolvimento da disciplina de Docência Orientada, na qual estabelece uma atuação e avaliação individualizada de cada docente, desse modo pode-se sublinhar uma necessidade de haver maiores esclarecimentos sobre a dinâmica da Docência Orientada antes de iniciar as aulas.

Por meio da Docência Orientada, as três docentes "revelam as múltiplas aprendizagens que vão se colocando nesse espaço/tempo de se identificarem e se produzirem professoras. A profissionalidade passa, também, por uma identificação com o espaço da docência" (OLIVEIRA, 2004, p. 154).

Outros estudantes indicam percepção diferente e defendem que todos ganharam com essa proposta, pois "ter três professores durante as aulas só tornam mais ricas. Gostei muito" (informação verbal) ${ }^{3}$. Afirmam ainda que é interessante uma vez que "uma complementa a ideia ou exemplo da outra. Diferente de outra disciplina onde as docentes orientadas parecem só explicar para a professora" (informação verbal)4; "ao invés de ter uma pessoa para tirar nossas dúvidas existem três e quando uma falava sempre tinha outra que complementava" (informação verbal) 5 .

Ao fazer tal consideração A10 levanta uma importante questão em relação ao cuidado que deve ser tomado quando existe uma avaliação da prática docente por uma professora orientadora. Tanto orientadora quanto docente precisam ter o discernimento de que o mais importante é a relação direta que precisa ser mantida com os estudantes e a professora naquele momento, portanto, a impressão exposta sobre a experiência vivida em outras disciplinas expõe uma fragilidade didática que deve ser corrigida. De outra forma, estes mesmos dizeres engrandecem o trabalho desenvolvido e as impressões após a experiência que foi desenvolvida na disciplina.

No desenvolvimento da Docência Orientada é primordial que ocorra preocupação constante em manter o diálogo entre os envolvidos (estudantes, docentes orientadas e orientadora), para isso lança-se várias propostas que possam incentivar as participações ativas por meio de seminários, dinâmicas, debates, oficinas, todas essas metodologias

\footnotetext{
1 Depoimento de estudante de um curso de licenciatura aqui identificada como A8 durante aula para a turma de Educação Especial em Universidade Pública do Rio Grande do Sul, no primeiro semestre de 2018.

2 Depoimento de estudante de um curso de licenciatura aqui identificada como A13 durante aula para a turma de Educação Especial em Universidade Pública do Rio Grande do Sul, no primeiro semestre de 2018.

3 Depoimento de estudante de um curso de licenciatura aqui identificada como A4 durante aula para a turma de Educação Especial em Universidade Pública do Rio Grande do Sul, no primeiro semestre de 2018.

4 Depoimento de estudante de um curso de licenciatura aqui identificada como A10 durante aula para a turma de Educação Especial em Universidade Pública do Rio Grande do Sul, no primeiro semestre de 2018.

5 Depoimento de estudante de um curso de licenciatura aqui identificada como A20 durante aula para a turma de Educação Especial em Universidade Pública do Rio Grande do Sul, no primeiro semestre de 2018.
} 
foram utilizadas para que houvesse o fortalecimento de empatias e confiança para a verbalização do pensamento, isso se dá por acreditar-se que quanto maior a interação entre os estudantes e professores mais produtividade e assimilação de conteúdos será alcançado.

Nesse seguimento, sustenta-se a ideia de que "um ambiente estimulante e agradável pode ser criado envolvendo os estudantes em atividades em que eles assumam um papel ativo e não sejam meros expectadores" (CONSENZA; GUERRA, 2011, p.48), e a aprendizagem para ser significativa precisa ser vivida e discutida no grupo. As falas dos estudantes A2, A17 e A22, respectivamente ilustram que tais objetivos foram alcançados: "A turma se entrosou bastante ao longo das aulas"(informação verbal) ${ }^{6}$; "Houve a liberdade para expressar, ficamos a vontade"(informação verbal) $)^{7}$; “As professoras são bem acessíveis" (informação verbal) ${ }^{8}$.

A ideia de Perrenoud (2002) da impossibilidade de formar um profissional reflexivo impondo-lhe condições ortodoxas de dar aula é oportuna, pois é o direcionamento que se segue quando o objetivo é estimular a participação dos estudantes ao longo de todas as aulas incentivando falas sobre suas impressões, sentimentos de forma a construir coletivamente uma prática que levem à aprendizagem significativa. Apresentam-se algumas manifestações: "Houve oportunidade para todos participarem das discussões, reflexões, só não participou quem não quis" (informação verbal) ${ }^{9}$; "Em todas as aulas havia dinâmica e todos podiam participar" (informação verbal) ${ }^{10}$; "Sempre abriram espaços para que pudéssemos dar nossas opiniões". (informação verbal)"1; "[...] elas faziam questão da participação e faziam questionamentos para os estudantes para a aula ficar mais motivada" (informação verbal) $)^{12}$.

${ }^{6}$ Depoimento de estudante de um curso de licenciatura aqui identificada como A2 durante aula para a turma de Educação Especial em Universidade Pública do Rio Grande do Sul, no primeiro semestre de 2018.

7 Depoimento de estudante de um curso de licenciatura aqui identificada como A17 durante aula para a turma de Educação Especial em Universidade Pública do Rio Grande do Sul, no primeiro semestre de 2018.

8 Depoimento de estudante de um curso de licenciatura aqui identificada como A22 durante aula para a turma de Educação Especial em Universidade Pública do Rio Grande do Sul, no primeiro semestre de 2018.

9 Depoimento de estudante de um curso de licenciatura aqui identificada como A4 durante aula para a turma de Educação Especial em Universidade Pública do Rio Grande do Sul, no primeiro semestre de 2018.

${ }^{10}$ Depoimento de estudante de um curso de licenciatura aqui identificada como A8 durante aula para a turma de Educação Especial em Universidade Pública do Rio Grande do Sul, no primeiro semestre de 2018.

${ }^{11}$ Depoimento de estudante de um curso de licenciatura aqui identificada como A13 durante aula para a turma de Educação Especial em Universidade Pública do Rio Grande do Sul, no primeiro semestre de 2018.

${ }^{12}$ Depoimento de estudante de um curso de licenciatura aqui identificada como A15 durante aula para a turma de Educação Especial em Universidade Pública do Rio Grande do Sul, no primeiro semestre de 2018. 
O estabelecimento de um espaço dinâmico e aberto para diálogos e problematizações faz com que o professor esteja cada vez mais preparado para responder os questionamentos advindos da turma, e isto tem se tornado uma competência essencial nesta profissão, e que foram levantados pelos estudantes como um quesito fundamental na atuação das docentes com relação ao domínio dos conteúdos, ficando claro quando informação verbal) ${ }^{13}$ afirma que "elas mostram domínio do conhecimento a partir das respostas das perguntas dos acadêmicos".

Além de favorecer a confiança e segurança das docentes orientadas que estão sob avaliação do professor orientador, as formas de responder frente às representações que surgem no dia-a-dia da sala de aula, também geram retornos positivos aos estudantes diante da experiência de ter duas docentes orientadas, sendo assim, influencia diretamente nas opiniões: "elas realmente sabem o que estão passando para os estudantes" (informação verbal) ${ }^{14}$; "conseguiram responder e tiraram as dúvidas que foram aparecendo" (informação verbal) ${ }^{15}$; "com certeza tinham domínio do conhecimento sobre o assunto que estavam passando" (informação verbal) ${ }^{16 ;}$; "explicaram super bem, não deixaram a desejar, foi tudo explicado com muita clareza" (informação verbal) ${ }^{17}$.

Conforme já explicitado, a Docência Orientada como uma disciplina que se desenvolve diretamente com pessoas em ciclos formativos precisa seguir uma rigorosidade metódica (FREIRE, 1996), na qual o ensino não seja reduzido à transmissão dos conhecimentos, pelo contrário, o ensino ocorre na relação professor e aluno, na qual todos são produtores do conhecimento.

Buscando caminhar nesta perspectiva lançou-se mão de várias estratégias, um dos destaques dados pelos entrevistados foi a realização de seminários, momento que oportunizou grande engajamento dos estudantes, e embora sempre houvesse aplicação de debates e dinâmicas, a possibilidade de estar à frente, na condição de aprendente, mas também ensinante incentivou e estimulou grande parte da turma. Sobre essa experiência destacam-se as seguintes falas: "A forma que organizaram a ementa da disciplina foi muito boa, principalmente a parte de Humberto Maturana"

${ }^{13}$ Depoimento de estudante de um curso de licenciatura aqui identificada como A21 durante aula para a turma de Educação Especial em Universidade Pública do Rio Grande do Sul, no primeiro semestre de 2018.

${ }^{14}$ Depoimento de estudante de um curso de licenciatura aqui identificada como A5 durante aula para a turma de Educação Especial em Universidade Pública do Rio Grande do Sul, no primeiro semestre de 2018.

${ }^{15}$ Depoimento de estudante de um curso de licenciatura aqui identificada como A6 durante aula para a turma de Educação Especial em Universidade Pública do Rio Grande do Sul, no primeiro semestre de 2018.

${ }^{16}$ Depoimento de estudante de um curso de licenciatura aqui identificada como A8 durante aula para a turma de Educação Especial em Universidade Pública do Rio Grande do Sul, no primeiro semestre de 2018.

${ }^{17}$ Depoimento de estudante de um curso de licenciatura aqui identificada como A11 durante aula para a turma de Educação Especial em Universidade Pública do Rio Grande do Sul, no primeiro semestre de 2018. 
(informação verbal) ${ }^{18}$. "Sugiro apenas que a gente pudesse participar mais como fez a professora Y que interagiu com a turma, quebrou aquele gelo de professor e aluno" (informação verbal) ${ }^{19}$.

As docentes orientadas não possuíram nenhuma participação sobre a criação do programa da disciplina, mas a execução dos saberes curriculares ali mencionados precisavam ser debatidos com os estudantes, momento em que houve a participação direta das docentes. Destaque-se que o momento posterior que engloba a organização de estratégias, datas, avaliações e metodologias utilizadas a cada encontro contou com a participação e análise das três docentes. Os estudantes opinaram sobre essa organização: "Achei bem dividido a matéria entre a professora e as duas docentes orientadas" (informação verbal) ${ }^{20}$; "Gostei das aulas assim" (A18); "A forma que organizaram a ementa da disciplina foi muito boa" (informação verbal) ${ }^{21}$.

Considera-se positivo que os estudantes continuem a refletir sobre os aspectos relativos às práticas docentes e organização curricular inclusive quando estiverem em pleno exercício, pois questões como necessidade de ampliação de carga horária para possibilitar mais aulas e diminuição do ritmo dado ao longo das explanações direcionam para uma revisão da dinâmica já instituída pela Universidade.

Entende-se que toda atuação docente é suscetível de imprevistos, isso não remete a um planejamento ineficaz, e precisam ser vistos como oportunidade de continuidade na Educação Superior da humanização (sempre incompleta) iniciada em níveis anteriores. Com isso, é importante mencionar que a prática pedagógica foi se tornando mais fluida a partir dessas experiências, estabelecendo relações entre a formação docente adquirida nos bancos da academia e o que era percebido a partir da atuação, dirigindo à reflexão e auto avaliação sobre as próprias práticas desenvolvidas.

\section{Dimensóes da docência sob a perspectiva dos estudantes}

$\mathrm{O}$ aprofundamento das questões concernentes à Docência Orientada especialmente no tocante à reflexão em torno dessa prática e dos possíveis aspectos positivos e negativos decorrentes da experiência de ter aula com docentes

\footnotetext{
${ }^{18}$ Depoimento de estudante de um curso de licenciatura aqui identificada como A21 durante aula para a turma de Educação Especial em Universidade Pública do Rio Grande do Sul, no primeiro semestre de 2018.

${ }^{19}$ Depoimento de estudante de um curso de licenciatura aqui identificada como A2 durante aula para a turma de Educação Especial em Universidade Pública do Rio Grande do Sul, no primeiro semestre de 2018.

${ }^{20}$ Depoimento de estudante de um curso de licenciatura aqui identificada como A15 durante aula para a turma de Educação Especial em Universidade Pública do Rio Grande do Sul, no primeiro semestre de 2018.

${ }^{21}$ Depoimento de estudante de um curso de licenciatura aqui identificada como A21 durante aula para a turma de Educação Especial em Universidade Pública do Rio Grande do Sul, no primeiro semestre de 2018.
} 
orientadas só foi possível com a participação dos estudantes, portanto, a escuta e o respeito às suas percepções são de antemão requisitos desta pesquisa.

É preciso realçar que em todo começo há inseguranças e dúvidas que podem surgir em todos os envolvidos e perpassam por vários aspectos: domínio de conteúdos, receptividade e aceitação, e outros aspectos que envolvem o processo ensino-aprendizagem. Isto foi ressaltado nas falas dos estudantes quando afirmam que "foi uma experiência nova, no início pensei que eu não iria conseguir aprender, mas depois vi que tudo é um aprendizado" (informação verbal) $)^{22}$. E também com A20: "Confesso que no início tive certo preconceito em relação às meninas em função de outros professores afirmarem que quem deve ministrar a aula é o professor, mas mudei minha opinião" (informação verbal $)^{23}$.

Essas manifestações remetem a Freire (1980) e sua proposta de incentivo constante pela busca do conhecimento por meio da interação em uma relação horizontal, com destaque ao respeito mútuo, rompendo com o modelo verticalizado de educação que oprime o aluno, pois nesse modelo o professor possui todo o conhecimento e, por conseguinte todas as respostas, enquanto o aluno se restringe a um sujeito passivo a quem deve ser dirigido um saber já elaborado e pronto.

Em relação à experiência com docentes orientadas pode-se afirmar que forneceu valiosas aprendizagens e experiências aos estudantes. A autonomia e confiança dada aos estudantes durante o desenvolvimento dos trabalhos em grupo foi um dos destaques feito por A3 quando afirma que "pesquisamos o trabalho se doando e conhecendo melhor" (informação verbal) ${ }^{24}$. As orientações eram dadas pontualmente a partir das necessidades individuais, estimulando-os para construção e elaboração de estratégias, e mesmo sem se darem conta já estavam no início do curso de licenciatura exercitando uma prática docente mais elaborada e reflexiva.

Ao longo das aulas com o desenvolvimento das diversas estratégias foi sendo percebido aquilo que já se conhecia por meio das leituras: não existe uma política ou fórmula voltada para a formação dos professores universitários. Evidenciou-se, no entanto, durante esta experiência que a relação entre conhecimentos teóricos e o cotidiano estimula a curiosidade e participação, elementos fundamentais para construção do conhecimento. Tal afirmação se dá diante

22 Depoimento de estudante de um curso de licenciatura aqui identificada como A2 durante aula para a turma de Educação Especial em Universidade Pública do Rio Grande do Sul, no primeiro semestre de 2018.

${ }^{23}$ Depoimento de estudante de um curso de licenciatura aqui identificada como A20 durante aula para a turma de Educação Especial em Universidade Pública do Rio Grande do Sul, no primeiro semestre de 2018.

${ }^{24}$ Depoimento de estudante de um curso de licenciatura aqui identificada como A3 durante aula para a turma de Educação Especial em Universidade Pública do Rio Grande do Sul, no primeiro semestre de 2018. 
das análises feitas sobre o ensino e aprendizagem: "cada uma colocando exemplos fica mais fácil de compreender o conteúdo" (informação verbal) ${ }^{25}$; "foram muito boas principalmente as dinâmicas onde houve melhor interação da turma, tornando mais fácil a assimilação do conteúdo" (informação verbal)26; "nos trouxeram mais para nosso dia a dia" (informação verbal) ${ }^{27}$.

Essa consciência de que os estudantes sofrem influências do meio em seu processo de aprendizagem fizeram com que a organização das aulas estimulasse a construção de novos conhecimentos ou o aprimoramento do que já existia por meio da (des) acomodação sempre no devir de suas experiências de vida e com exemplos que pudessem ser visualizados. Acredita-se que a capacidade de vincular teoria e prática para tornar a aprendizagem mais significativa, seja uma competência fundamental no decurso do exercício da docência, isso é percebido na seguinte fala "[...] usaram a teoria com a prática conosco, isso valorizou muito" (informação verbal) ${ }^{28}$.

Sequentemente, ainda em relação à experiência vivenciada pelos estudantes durante a Docência Orientada sublinha-se a fala de A6 na qual afirma que "assim podemos ter vários pontos de vista sobre o mesmo assunto" (informação verbal) ${ }^{29}$. O estudante identificou a possibilidade de ampliação e aprofundamento da aprendizagem com três docentes e valorizou o exercício da docência desenvolvido pelas mestrandas.

Adiante se constata considerações que dão ênfase para uma experiência rica, demonstrando credibilidade dos conhecimentos ensinados pelas mestrandas e em suas competências relacionadas ao domínio do conteúdo; A15 “[...] estavam bem preparadas e confiantes no que estavam apresentando"(informação verbal) ${ }^{30}$; A18 "[...] tivemos aula de maneiras diferentes, cada uma na sua forma de explicar o conteúdo" (informação verbal) ${ }^{31}$ e A21 “[...] elas vinham

${ }^{25}$ Depoimento de estudante de um curso de licenciatura aqui identificada como A10 durante aula para a turma de Educação Especial em Universidade Pública do Rio Grande do Sul, no primeiro semestre de 2018.

${ }^{26}$ Depoimento de estudante de um curso de licenciatura aqui identificada como A24 durante aula para a turma de Educação Especial em Universidade Pública do Rio Grande do Sul, no primeiro semestre de 2018.

${ }^{27}$ Depoimento de estudante de um curso de licenciatura aqui identificada como A22 durante aula para a turma de Educação Especial em Universidade Pública do Rio Grande do Sul, no primeiro semestre de 2018.

${ }^{28}$ Depoimento de estudante de um curso de licenciatura aqui identificada como A3 durante aula para a turma de Educação Especial em Universidade Pública do Rio Grande do Sul, no primeiro semestre de 2018.

${ }^{29}$ Depoimento de estudante de um curso de licenciatura aqui identificada como A6 durante aula para a turma de Educação Especial em Universidade Pública do Rio Grande do Sul, no primeiro semestre de 2018.

${ }^{30}$ Depoimento de estudante de um curso de licenciatura aqui identificada como A15 durante aula para a turma de Educação Especial em Universidade Pública do Rio Grande do Sul, no primeiro semestre de 2018.

${ }^{31}$ Depoimento de estudante de um curso de licenciatura aqui identificada como A18 durante aula para a turma de Educação Especial em Universidade Pública do Rio Grande do Sul, no primeiro semestre de 2018. 
preparadas. Sempre respondiam os questionamentos da turma com paciência. Dominavam o conteúdo que trouxeram para a sala de aula" (informação verbal) ${ }^{32}$.

Com a proposição de defender a prática reflexiva dentro da profissão docente não há como deixar de apresentar as opiniões críticas referentes à experiência desenvolvida na sala de aula, dessa forma A12 destaca que "no geral foi bem bom, algumas coisas ficamos com dúvidas, mas a professora conseguia esclarecer" (informação verbal) ${ }^{33}$. Observa-se por meio da fala que ainda há um pensamento arraigado na estrutura de hierarquização do espaço, pois a "professora" essencialmente constituída e, portanto apta a esclarecer a dúvida neste caso é a professora orientadora.

O mesmo ocorre quando A14 revela ser favorável à experiência, sua fala positiva sobre o conhecimento das mestrandas incute ao mesmo tempo a internalização da falta de confiança ou a surpresa em relação à capacidade das docentes orientadas "foi ótima, pois apesar de docentes orientandas elas possuíam bastante conhecimento sobre o assunto que estavam nos ensinando" (informação verbal) 34 , outro aspecto, destacado por A19 é que as docentes orientadas "[...] deveriam explicar o conteúdo mais devagar" (informação verbal) ${ }^{35}$.

Perrenoud (2002) considera que a postura prática reflexiva torna-se corriqueira quando a análise das práticas e dos funcionamentos está na origem dos ajustes, portanto, a postura defensiva frente às críticas não pode dominar o pensamento ou a ação de um professor reflexivo, pois este precisa aprender a lidar com as diversas situações e dominá-las. Nessa ótica, os pontos levantados pelos estudantes devem possibilitar a melhoria constante das práticas.

Considerando todos os aspectos positivos e negativos sinalizados pelos estudantes que acompanharam a atuação das mestrandas durante a disciplina, acredita-se que isto repercutirá para as práticas futuras não apenas das mestrandas que ocupavam o lugar de docentes orientadas, mas também dos próprios estudantes da graduação que mesmo iniciando recentemente a Educação Superior e seu processo formativo já puderam refletir sobre as fragilidades e sucessos da formação profissional.

${ }^{32}$ Depoimento de estudante de um curso de licenciatura aqui identificada como A21 durante aula para a turma de Educação Especial em Universidade Pública do Rio Grande do Sul, no primeiro semestre de 2018.

${ }^{33}$ Depoimento de estudante de um curso de licenciatura aqui identificada como A12 durante aula para a turma de Educação Especial em Universidade Pública do Rio Grande do Sul, no primeiro semestre de 2018.

${ }^{34}$ Depoimento de estudante de um curso de licenciatura aqui identificada como A14 durante aula para a turma de Educação Especial em Universidade Pública do Rio Grande do Sul, no primeiro semestre de 2018.

${ }^{35}$ Depoimento de estudante de um curso de licenciatura aqui identificada como A19 durante aula para a turma de Educação Especial em Universidade Pública do Rio Grande do Sul, no primeiro semestre de 2018. 
Embora o contato com a profissão docente se faça desde muito cedo na escola o aprofundamento que poderá levar a utilização mais adequada de estratégias só será possível após os estudos e práticas, estas por sua vez são compostas por uma bagagem de conhecimentos anteriores, crenças, representações e certezas sobre a prática docente (TARDIF, 2002). Dessa forma, cada um a partir dessa experiência irá poder organizar sua bagagem de acordo com o que acredita ser importante carregar para a atuação docente após a sua formação.

Logo, indicadores positivos apontados pelos estudantes versaram sobre diferentes aspectos. Um deles é em relação às dinâmicas realizadas fazendo com que a aula ficasse atrativa e facilitando a apropriação dos conteúdos, como menciona A22 "foi positiva, pois foi uma aula que não era cansativa e que nos fez entender bem, pois sempre as aulas foram lúdicas, e bem apresentadas" (informação verbal) ${ }^{36}$; “[...] aulas produtivas, capazes de mexer com nossa imaginação, criação de grupos, aula com uma ótima qualidade" (informação verbal) ${ }^{37}$.

Segundo Franco (2008a) muitas vezes existe uma dificuldade do professor realizar na prática, o que pensa, discursa, ou teoriza, limitando-se a uma prática não reflexiva e mecanizada, dando a impressão de que o professor abandona sua consciência ao entrar em situação prática. Assim, esta provocação era debatida ao término das aulas pelas docentes que buscavam analisar em conjunto se o discurso caminhava lado a lado com a prática pretendida.

Ao se pensar em uma turma que está iniciando a formação inicial e com pessoas que nunca se viram necessita que o professor envolva em suas práticas atividades lúdicas que favoreçam a convivência, a amizade, e isto também ficou frisado na resposta de A21 "[...] foi uma aula dinâmica, onde os estudantes e professores interagiram um com o outro" (informação verbal) ${ }^{38}$.

O professor não pode preocupar-se apenas com o ensinamento dos conhecimentos, mas também com as formas que serão ensinadas, quais procedimentos serão utilizados, e estas premissas encontra-se com o que foi elencado de positivo na experiência vivenciada. Para que isto ocorra tem que haver a disposição para o diálogo e o reconhecimento de que "ensinar não é transferir conhecimento, mas criar possibilidades para a sua produção ou a sua construção" (FREIRE, 1996, p. 22).

${ }^{36}$ Depoimento de estudante de um curso de licenciatura aqui identificada como A22 durante aula para a turma de Educação Especial em Universidade Pública do Rio Grande do Sul, no primeiro semestre de 2018.

${ }^{37}$ Depoimento de estudante de um curso de licenciatura aqui identificada como A13 durante aula para a turma de Educação Especial em Universidade Pública do Rio Grande do Sul, no primeiro semestre de 2018.

${ }^{38}$ Depoimento de estudante de um curso de licenciatura aqui identificada como A21 durante aula para a turma de Educação Especial em Universidade Pública do Rio Grande do Sul, no primeiro semestre de 2018. 
Salienta-se que esta perspectiva na qual o estudante possui papel ativo na busca do conhecimento esteve intimamente vinculado aos conteúdos durante as aulas, o que resultou em "[...] conteúdos bem explicados. Trabalhos bem elaborados, com ótimas dinâmicas" (informação verbal) ${ }^{39}$.

Para os estudantes A8, A11, A15, A19 e A21 a atuação de três docentes na sala de aula foi muito importante, pois "[...] a oportunidade de ter três professoras para nos passar os conteúdos e responder as dúvidas" (informação verbal) ${ }^{40}$ facilita a compreensão dos conteúdos ensinados. $O$ trabalho em equipe entre as docentes ficou visível para os estudantes, sendo enfatizado por A15 quando diz que "[...] cada uma tem seu jeito de explanar o conteúdo [...]. A professora enriquecia as explicações, interagindo com as orientandas" (informação verbal $)^{41}$.

Infere-se ainda que a credibilidade do docente perante os estudantes é sentida nas formas de expressão, posturas, afetividade, aquele professor "[...] que não leve a sério a sua formação, que não estude, que não se esforce para estar à altura de sua tarefa não tem força moral para coordenar as atividades de sua classe" (FREIRE, 1996, p. 92), e estas são qualidades profissionais fundamentais no exercício da docência.

Quando o olhar se volta para a Educação Superior onde se presume maior percepção e avaliação crítica ao professor e suas práticas podem figurar para os futuros educadores como exemplo positivo a ser seguido quando se observa a preocupação docente com a qualificação, ética, pesquisa e criticidade. Foi o que registrou A14 ao dizer que "[...] esse tipo de educação deveria ser aumentado nas escolas e universidades brasileiras, pois quando há interesse verdadeiro da parte das docentes e professora isso só tende a contribuir para ambas as partes" (informação verbal $)^{42}$, revelando que as aulas dinâmicas, o engajamento profissional deveria ser mais recorrente em todas as disciplinas.

Os aspectos negativos também constituem a identidade profissional, é o que move, que faz indagar, mudar, progredir, e mostrar que além da auto avaliação realizada pelo professor, os estudantes têm muito a contribuir. Com relação à presença de três docentes um aspecto negativo foi que "[...] às vezes, as três querendo explicar a mesma

${ }^{39}$ Depoimento de estudante de um curso de licenciatura aqui identificada como A18 durante aula para a turma de Educação Especial em Universidade Pública do Rio Grande do Sul, no primeiro semestre de 2018.

${ }^{40}$ Depoimento de estudante de um curso de licenciatura aqui identificada como A8 durante aula para a turma de Educação Especial em Universidade Pública do Rio Grande do Sul, no primeiro semestre de 2018.

${ }^{41}$ Depoimento de estudante de um curso de licenciatura aqui identificada como A15 durante aula para a turma de Educação Especial em Universidade Pública do Rio Grande do Sul, no primeiro semestre de 2018.

${ }^{42}$ Depoimento de estudante de um curso de licenciatura aqui identificada como A14 durante aula para a turma de Educação Especial em Universidade Pública do Rio Grande do Sul, no primeiro semestre de 2018. 
coisa nos deixaram meios confusos. Mas foram aulas muito boas" (informação verbal) ${ }^{43}$. Nesse direcionamento acrescenta-se A10 quando enuncia que "[...] gostaria de dar um conselho que quando tiver algum trabalho que ambas esclareçam a mesma coisa, pois esses dias fui tirar uma dúvida e cada uma das orientandas falou uma coisa. Fora este destaque não tenho nada mais a dizer" (informação verbal) ${ }^{44}$.

Diante da preocupação com a atuação na sala, com o processo ensino-aprendizagem algumas questões passam despercebidas, por algum descuido ou falha na comunicação entre as docentes, o que mostra a necessidade constante de atenção do professor em todos os aspectos.

Assim, compreende-se que o profissional da educação constitui-se na formação individual e coletiva. Grande parte do que foi exposto não poderia ser adquirido nos cursos de formação, e sim no chão da sala de aula, no exercício da docência, imbricado com a prática reflexiva. Essas percepções fortalecem os propósitos deste artigo e engrandecem a Docência Orientada como um importante (pré) requisito para tornar-se docente na Educação Superior.

\section{Considerações finais}

As problematizações aqui propostas assinalam elementos considerados basilares para a trajetória de formação docente na Educação Superior. Com isso, teve-se como objetivo geral investigar as percepções dos estudantes de um curso de licenciatura em relação à Docência Orientada sendo elencados alguns questionamentos sobre a metodologia e a organização do programa fazendo emergir avaliações positivas sobre o espaço para participação ao longo das aulas e o domínio do conteúdo por parte das docentes orientadas.

Com base nos dados coletados conclui-se que a Docência Orientada contribuiu para a apropriação dos conhecimentos ensinados durante a disciplina, principalmente pela presença de três docentes na sala, estabelecimento de uma aprendizagem significativa e concreta através das dinâmicas, atividades lúdicas, incentivos a trabalhos em grupos, pesquisas, interações entre os colegas, o que potencializa a aprendizagem. O trabalho coletivo contribuiu para a qualidade no planejamento e dinamização das aulas, compartilhando ideias, saberes e fazeres entre as docentes orientadas, a professora docente e os alunos.

${ }^{43}$ Depoimento de estudante de um curso de licenciatura aqui identificada como A22 durante aula para a turma de Educação Especial em Universidade Pública do Rio Grande do Sul, no primeiro semestre de 2018.

${ }^{44}$ Depoimento de estudante de um curso de licenciatura aqui identificada como A10 durante aula para a turma de Educação Especial em Universidade Pública do Rio Grande do Sul, no primeiro semestre de 2018. 
Ainda, pode-se finalizar que a dedicação e apropriação dos conhecimentos pelas docentes orientadas fez com que houvesse vinculação entre teoria e prática.

Com relação ao objetivo de analisar os documentos que orientam a prática da Docência Orientada na Instituição desfecha-se que ao exercício da Docência Orientada incumbem-se os mesmos comprometimentos, ética e deveres profissionais, principalmente porque influencia diretamente na formação inicial dos graduandos, e também porque são obrigatórias e básicas na formação.

Quanto aos objetivos de refletir sobre as concepções da Docência Orientada no processo formativo dos estudantes do curso de licenciatura e discutir sobre aspectos positivos e negativos da Docência Orientada elencados pelos estudantes do curso de Licenciatura, infere-se que é necessário fazer ajustes em relação à forma de apresentação da proposta aos estudantes da Graduação. Algumas possibilidades é que se dedique um tempo maior para explanar aos alunos da graduação como se dará a dinâmica da disciplina, sempre que se diferenciar da forma tradicionalmente conhecida; que seja elucidado, desde o início, como ocorrerá a divisão dos conteúdos entre as mestrandas; que a prática possa trabalhar um cronograma flexível; e por fim, diante do potencial formativo para todos os envolvidos, que se reflita sobre a importância da ampliação dessa metodologia.

Com relação ao objetivo de incentivar o pensamento crítico-reflexivo dos estudantes da graduação sobre a prática da Docência Orientada encorajando a verbalização de suas concepções sobre tal experiência, conclui-se que favorece diretamente a prática reflexiva docente, faz repensar principalmente sobre as posturas docentes e a organização de procedimentos didáticos.

Acredita-se que a universidade, ao ofertar a Docência Orientada nos cursos de Mestrado e Doutorado de forma articulada com a Graduação, fortalece, não apenas a prática, mas também a pesquisa, uma vez que fornecerá instrumentos teóricos e avaliação constante do docente orientado pelo professor orientador, possibilitando a melhoria das ações voltadas ao ensino.

A pretensão deste estudo não foi tecer juízo de valor sobre comportamentos ou ações, mas discutir sobre a importância da Docência Orientada bem como a prática docente de mestrandas, por isso partiu-se do interesse em perceber a ótica dos estudantes a quem foi dirigida tal práxis docente, sendo, portanto as vozes que precisam ocupar lugar central.

Sugere-se que os estudantes de Mestrado e Doutorado possam vivenciar essa experiência ao longo dos seus cursos para que consigam desenvolver-se não apenas como pesquisadores, mas em uma perspectiva que contemple uma formação docente mais ampla capaz de atender aos requisitos epistemológicos, metodológicos e científicos que a educação de qualidade exige.

Esta pesquisa, assim como tantas outras em Educação não pode ser repetida, e isso a deixa tão particular e única, por isso, apresentou-se especialmente detalhada, pois se considera o ato educativo mutante. Dessa forma, 
torna-se impossível ofertar condições e sujeitos idênticos aos envolvidos, assim, é imprescindível que esta discussão não se esgote e que possa ser dada continuidade e ampliação ao debate dentro das universidades e entre os próprios mestrandos e doutorandos.

\section{Referências}

BARDIN, Laurence. Análise de conteúdo. São Paulo: Edições 70, 2011.

BRASIL. Lei no 9.394, de 20 de dezembro de 1996. Estabelece as Diretrizes e Bases da Educação Nacional. Brasília, DF: Presidência da República, 1996. Disponível em: http://www.planalto.gov.br/ccivil_03/leis/L9394.htm. Acesso em: 28 nov. 2016. https://doi.org/10.11606/d.7.2013.tde-10092013-151829

COSENZA, R. M.; GUERRA, L. Neurociência e educação: como o cérebro aprende. Porto Alegre: Artmed, 2011.

FRANCO, M. A. S. Entre a lógica da formação e a lógica das práticas: a mediação dos saberes pedagógicos. Revista Educação e Pesquisa, São Paulo, v. 34, n. 1, p. 109-126, jan./abr. 2008a. https://doi.org/10.1590/s1517-97022008000100008

FRANCO, M. A. S. Pedagogia como ciência da educação. 2. ed. São Paulo: Cortez, 2008 b.

FREIRE, Paulo. Educação como prática da Liberdade. Rio de Janeiro: Paz e Terra, 1980.

FREIRE, P. Pedagogia da Autonomia: Os sete saberes necessários à prática educativa. São Paulo: Paz e Terra, 1996. https://doi. org/10.9771/2317-1219rf.v13i13.3221

ISAIA, S.; CUNHA, M. Professor da Educação Superior. In: MOROSINI, Marília Costa (org.). Enciclopédia de Pedagogia Universitária. Brasília, DF: INEP/MEC, 2006. v. 2. p.349-405. Disponível em: http://portal.inep.gov.br/ documents/186968/484184/Enciclop\%C3\%A9dia+de+pedagogia+universit\%C3\%A1ria+gloss\%C3\%A1rio+vol+2/b9d6f55d-178046ef-819a-cdc81ceeac39?version=1.0. Acesso em: 18 dez. 2018. https://doi.org/10.11606/d.59.2019.tde-01102018-113154

NEUENFELDT, Manuelli Cerolini. A Docência Orientada como caminho possível no processo formativo de professores universitários: em busca de Indicadores de Qualidade. 2008. 198f. Dissertação (Mestrado em Educação) - Universidade Federal de Santa Maria, Santa Maria, 2008. https://doi.org/10.21840/siic/147814

OLIVEIRA, Valeska Fortes de. Docência Orientada: Aprendizagens compartilhadas no ensino universitário. Revista Olhar de Professor, Ponta Grossa, v. 7, n. 1, p. 149-160, 2004. Disponível em: http://www.revistas2.uepg.br/index.php/olhardeprofessor/ article/view/1421/1066. Acesso em: 18 dez. 2018. 
OLIVEIRA, C. C.; VASCONCELLOS, M. M. M. A formação pedagógica institucional para a docência na Educação Superior. Revista Interface Botucatu, São Paulo, v. 15, n. 39, p. 1011-1024, out./dez. 2011. https://doi.org/10.1590/s141432832011005000024

PERRENOUD, P. Dez novas competências para ensinar. Tradução: Cláudia Schilling e Fátima Murad. Porto Alegre: Artes Médicas Sul, 2000.

PERRENOUD, P. A formação dos professores no século XXI. In: PERRENOUD, Philippe; THURLER, Monica Gather; MACEDO, Lino de; MACHADO, Nilson Jose; ALESSANDRINI, Cristina Dias (org.). As competências para ensinar no século XXI: a

formação dos professores e o desafio da avaliação. Porto Alegre: Artmed, 2002, p. 11-34. https://doi.org/10.36229/978-85-7042-1661.cap.03

PRODANOV, C. C.; FREITAS, E. C. de F. Metodologia do trabalho científico [recurso eletrônico]: métodos e técnicas da pesquisa e do trabalho acadêmico. 2. ed. Novo Hamburgo: Feevale, 2013.

SAMPIERI, R. H.; COLlADO, C. H.; LUCIO, P. B. Metodologia da Pesquisa. Tradução: Daisy Vaz de Moraes. 5. ed. Porto Alegre: Penso, 2013.

SCHÖN, D. A. Educando o profissional reflexivo: um novo design para o ensino e a aprendizagem. Tradução: Roberto Cataldo Costa. Porto Alegre: Artmed, 2000.

TARDIF, M. Saberes docentes e formação profissional. 4. ed. Rio de Janeiro: Vozes, 2002.

VEIGA, I. P. A. A aventura de formar professores. 2. ed. Campinas: Papirus, 2012.

Recebido em: 19/4/2018.

Aprovado em: 20/12/2019.

Publicado em: 17/4/2020.

\section{Endereço para correspondência:}

Mariane Carloto da Silva

Universidade Federal de Santa Maria - Centro de Educação

Av. Roraima, 1000, Prédio 16, Sala 3169 - Camobi

97105-900, Santa Maria, RS, Brasil 


\section{Autoras:}

Mariane Carloto da Silva

Universidade Federal de Santa Maria - Centro de Educação

Orcid: http://orcid.org/0000-0001-5065-975X

E-mail: mariane.carloto@gmail.com

\section{Sandra Regina Costa Pereira}

Universidade Federal de Santa Maria - Centro de Educação

Orcid: https://orcid.org/0000-0002-0473-7718

E-mail: srcpereira@gmail.com

Silvia Maria de Oliveira Pavão

Universidade Federal de Santa Maria - Centro de Educação

Orcid: http://orcid.org/0000-0002-5365-0280

E-mail: silviamariapavao@gmail.com 